Al-Azhar Bull. Sci. Vol. 18, No. 1 (June.): pp. 1-14, 2007.

\title{
SPECTRAL P-WAVE MAGNITUDES, MAGNITUDE SPECTRA AND OTHER SOURCE PARAMETERS FOR THE 1990 SOUTHERN SUDAN AND THE 2005 LAKE TANGANYIKA EARTHQUAKES
}

\section{HESHAM HUSSEIN MOHAMED MOUSSA}

Seismology Department, National Research Institute of Astronomy and Geophysics, Helwan 11421, Cairo, Egypt.

\begin{abstract}
Teleseismic Broadband P-wave seismograms radiated by May 1990 Southern Sudan and December, 2005 Lake Tanganyika earthquakes at different azimuths have been analyzed on the basis of magnitude spectra. The two earthquakes represent the largest shocks in the East African Rift System and its extension in southern Sudan. Both events have the same surface wave magnitude $\left(M_{S}=7.2\right)$. The maximum average spectral magnitude for the first event was determined as 6.79 at 4 seconds period compared to 6.33 at 4 seconds period estimated from the second event. The other source parameters for the two earthquakes were also estimated. The first event had a seismic moment over fourth that of the second event. The two events are radiated from patches of faults having radii of 13.05 and $7.85 \mathrm{~km}$ respectively. The average displacement and stress drop are estimated to be $0.56 \mathrm{~m}$ and $1.65 \mathrm{MPa}$ for the first event and $0.43 \mathrm{~m}$ and $2.20 \mathrm{MPa}$ for the second one. The source parameters, which describe inhomgeneity of the fault, are also determined from the magnitude spectra. These additional parameters are complexity, asperity radius, displacements across the asperity and ambient stress-drop. Both events produce moderate rupture complexity. Compared to the second event, the first event is characterized by relatively higher complexity, a low average stress-drop and a high ambient stress. A reasonable explanation for the relative variations in these parameters is that the source for each event is located at different tectonic environments. The focal mechanism solutions supplement such observation.
\end{abstract}

\section{Introduction}

In the recent years, two earthquakes of magnitude $\left(M_{S}=7.2\right)$ struck the East African Rift System and its extension in the Southern Sudan. The first one struck the most southern part of Sudan at the border with Uganda, about $50 \mathrm{~km}$ east of the Upper River Nile on 20 May, 1990 while the second one struck Tanganyika lake region, Congo-Tanzania and its surroundings on December 12, 2005 (Fig. 1) The first event is believed to be the largest earthquake ever recorded in Sudan since the beginning of the instrumentally recorded seismicity. The shock was felt in Sudan, Uganda and Kenya. At Juba area of Sudan, some buildings were damaged. According to the seismic history of the region, the area of the 1990 earthquake had been recognized as the site of two large earthquakes in 1850 and 1915 with a very low seismicity compared to the East African Rift system (Ambraseys and Adam, 
1986). The relocated aftershocks indicate that the western branch of the Esat African Rift System propagates into the Southern Sudan Rift (Girdler and McConnel, 1994). The 1990 event was interpreted as left lateral motion along a NW-SE striking fault plane (Gaulon et al., 1992). The orientation of this nodal plane is parallel to Aswa Shear Zone (ASZ) (Girdler and McConnel, 1994) as shown in Fig.1. The latter joins the southeastern trending Sudan and Anza (Kenya) rifts with the northern part of the East African Rift system (Barazangi, 1983; Gaulon et al., 1992). It is a Late Precambrian large transverse structural feature which is characterized by horizontal left lateral reactivation movement during Cenozoic (Gaulon et al., 1992). The seismogenic area was also affected by shear zones parallel to ASZ suggesting that a structure parallel to ASZ is responsible for 1990 earthquake (Girdler and McConnel, 1994).

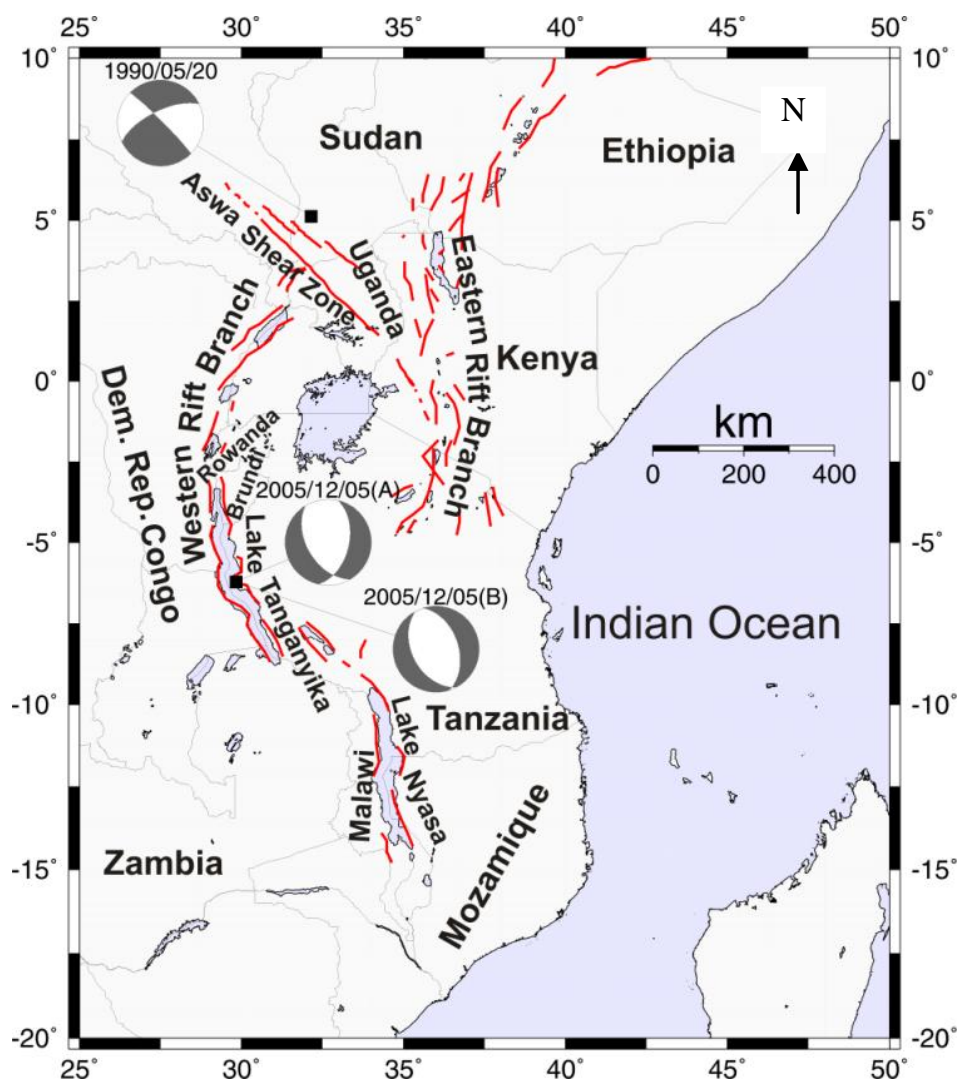

Fig.1. Focal mechanisms and epicenters for events used in this study area and the main East African Rift bounding faults. The 2005/12/05(A) is the Harvard CMT solution while 2005/12/05(B) is the NEIS solution. 
The second event took place along the East African Rift valley approximately below the surface of Lake Tanganyika. The most widespread damage was reported at Kalemie, Congo where 300 houses were destroyed; a church was collapsed and at least six people were killed. It was also felt in Brundi, Tanzania, Rwanda, Uganda and Kenya. Lake Tanganyika is a part of the western branch of the $3000 \mathrm{~km}$ long East African rift system extending from Afar to Mozambique (Rolet et al., 1991). The East African Rift (EAR) is the most active continental rift which is a part of a spreading system that includes the Red Sea and the Gulf of Aden. This rift system broke apart the African and Arabian plates and it is further breaking apart the African plate. Rifting within East Africa began at the Afar triple junction approximately 25-40 million years ago and has since propagated southwards at an estimated rate of 2-5 cm/yr. (Oxburg and Turcotte, 1974). The Harvard CMT of Tanganyika event shows almost pure normal faulting mechanism on nodal planes striking at NNW and NNE respectively. However, the solution of NEIS also shows pure normal faulting mechanism, but with both nodal planes striking at NNW and dipping to ENE and WSW respectively. The two solutions suggest E-W to ENEWSW trending extension, approximately perpendicular to the rift.

The main objectives of this study is to extract the source parameters of the 1990 Southern Sudan and the 2005 Lake Tanganyika earthquakes and to quantify the individual features of radiation process at the hypocenter from the teleseismic observations, based on the concept of magnitude spectra. The reality of the source parameters (fault length, seismic moment, stress drop and total seismic energy) derived from the spectral magnitudes depends on the determination of the corner period. Therefore, two methods were used to obtain this corner period. In this study, the asperity parameters (area and stress-drop) were also estimated assuming inhomogeneous fault model. Studying the source parameter of the individual events provides a potential data for earthquake engineering.

\section{Method Of Analysis}

In this work, the spectral magnitude technique has been applied to the two largest earthquakes that have been occurred in Lake Tanganyika of the East African Rift and its extension in the area of Southern Sudan Rift, using teleseismic broadband P waveform records. The concept of the spectral magnitude represents an updating of the magnitude and magnitude determination procedure. The spectral magnitude technique has been discussed by Sarker and Duda, 1985; Kaiser and Duda, 1986 and Chowdhury and Duda, 1986). It is a generalization of the body wave 
magnitude. The body wave magnitude of a particular earthquake constitutes discrete samples of velocity density spectrum. The samples, being averaged corresponding to period ranges, are not always specified. The sampling of the spectra is strongly influenced by the band pass of the different seismometer-galvanometer systems. Therefore, different instruments usually yield different magnitude values for a given earthquake. Moreover, the body wave magnitude for the narrow-band systems (e.g. WWSSN) were widely used to quantify the P-wave radiation at periods usually shorter than the one of the maximum radiation. However, the introduction of broadband observations gives us an opportunity to record the whole spectrum of the signal in a wider band frequency range than that from the narrow band instruments. Applying a set of non overlapping narrow band pass filters, separated from each other by short increment to the broad band records, a number of band pass seismograms are obtained from which body wave magnitudes corresponding to the respective set of seismograms can be estimated. These are known as spectral magnitudes. The obtained sequence of spectral magnitudes is called the magnitude spectrum. The magnitude spectrum is a quasi-continuous estimate of the velocity density spectrum of the $\mathrm{P}$-waves expressed in magnitude units. It represents the complete P-wave energy radiated from the source. The maximum of the magnitude spectrum and the corresponding period are the most characteristic quantities of the radiated spectrum for seismic events.

The magnitude spectrum $\mathrm{M}_{\mathrm{S}}(\mathrm{T})$ for a certain period $\mathrm{T}$ is related to the velocity density spectrum $S_{I}(T)$ through the following relation (Duda and Yanovskaya, 1994):

$$
M_{S}(T)=S_{I}(T)+\sigma_{I}(\Delta, h, T)
$$

Where I refers to either the vertical $(\mathrm{Z})$ or radial $(\mathrm{R})$ component and $\sigma_{\mathrm{I}}(\Delta, \mathrm{h}, \mathrm{T})$ is the $\mathrm{P}$ wave spectral calibration function on the basis of IASPI 91 velocity model and PREM Q models. $\Delta$ is the epicenteral distance and $\mathrm{h}$ is the focal depth. The spectral magnitudes are estimated in frequency intervals with a moving average window having a width of one octave. Plotting the spectral magnitudes versus the period allow to estimate the corner period $\left(\mathrm{T}_{\mathrm{o}}\right)$ of the maximum value of the spectral magnitudes.

Following Kaiser and Duda (1988), the source parameters can be extracted using the $\mathrm{P}$-wave magnitude spectrum which permits one to recognize the $\mathrm{T}_{0}$ directly as the one corresponding to the maximum value of the magnitude spectrum $\left(\mathrm{m}_{\mathrm{f}}\right)_{\max }$. 
The corner period $\left(\mathrm{T}_{0}\right)$ is related to seismic moment $\left(\mathrm{M}_{\mathrm{O}}\right)$ through the empirical relation,:

$$
M_{O}=10^{\left(m_{f}\right)_{\max }-0.7} T_{O}\left[\frac{2 \cdot \rho_{r} \cdot C_{r} \cdot C_{S}{ }^{4}}{\pi R_{\theta \phi}{ }^{2}}\right]^{1 / 2}
$$

where $\rho(r)$ is the density near the receiver, taken to be $2720 \mathrm{~kg} \mathrm{~m}^{-3}, \mathbf{C}_{\mathbf{r}}$ and $\mathbf{C}_{\mathbf{s}}$ the $\mathrm{P}$-wave velocities near the receiver and the source respectively are assumed to be $6100 \mathrm{~m} / \mathrm{s}$ and $5800 \mathrm{~m} / \mathrm{s}$ respectively and $R_{\theta \phi}$, the average radiation pattern coefficient, is given as a mean value of 0.44 .

The values of the corner periods can be used for estimating the fault radius of the seismic sources, using the model of Brune (1970, 1971) for a circular fault rupture is given by:

$$
a_{o}=0.37 \cdot C_{S} T_{0}
$$

To estimate the fault length $\mathrm{L}$, the approximation that the fault length equals to $\mathbf{2 a}_{\mathbf{0}}$ was used. Thus:

$$
L=0.74 . C_{S} T_{0}
$$

The values of $\mathbf{M}_{\mathbf{O}}$ and $\mathbf{a}_{\mathbf{0}}$ determined as described above, were used for estimation of the stress drop $(\Delta \boldsymbol{\sigma})$ from the following equation:

$$
\Delta \sigma=\frac{7}{16} \frac{M_{0}}{a_{0}^{3}}
$$

(Keilis-Borok, 1959) as well as for the estimation of the average displacement $\left(D_{0}\right)$ over a circular fault area is given from the equation:

$$
D_{0}=\frac{M_{0}}{\pi a_{0}^{2} \mu}
$$

where $\boldsymbol{\mu}$, the shear modulus of the fault material (Brune, 1968), is assumed to be $2.7 \times 10^{10} \mathrm{~Pa}$.

Due to difficulties in the determination of the corner period $\left(\mathbf{T}_{\mathbf{0}}\right)$ visually, at which the maximum magnitude occurs especially for complex source process earthquakes, the corner period was also estimated from the smoothed spectra, using 
another two different approaches following Duda and Kaiser, 1989. The first one is the corner period $\left(\mathbf{T}_{\mathrm{S}}\right)$, estimated from the equation:

$$
T_{S}=\frac{\pi R_{\theta \phi} 10^{\left(m_{f}\right)_{\max }-1.4}}{E_{P}}
$$

(Snoke, 1987) where $\mathbf{E}_{\mathbf{P}}$ is the total $\mathrm{P}$ wave energy radiated from the earthquake focus corrected for the signal outside the considered frequency band as proposed by Duda and Kaiser, 1989 , is given by :

$$
E_{p}=\int_{0}^{\infty} E_{p}(f) d f
$$

The energy spectral density of the source, $E_{p}(f)$, is related to the magnitude spectrum $m(f)$ through;

$$
E_{p}(f)=10^{2 m(f)-1.4}
$$

$\mathrm{T}_{\mathrm{S}}$ in equation (6) is the corner period of the P-wave magnitude spectrum with total $\mathrm{P}$-wave energy $\left(\mathrm{E}_{\mathrm{P}}\right)$ and with maximum magnitude $\mathrm{m}_{\mathrm{f}}(\max )$ as determined from the observed spectrum, but with a shape corresponding to omega-square spectrum for the P-wave (Aki, 1967; Brune,1970).

The second approach for measuring the corner period is the location of the first moment of the energy density spectrum, following the equation:

$$
T_{C}=\frac{E_{P}}{\int_{0}^{\infty} E_{P}(f) f d f}
$$

$\mathbf{T}_{\mathbf{C}}$ represents a weighted average value in case of complex spectra with several maxima. The rupture complexity can be measured using $\mathrm{T}_{\mathbf{c}}$ and $\mathbf{T}_{\mathbf{S}}$ defined by equations (7) and (8) through the following relation (Duda and Kaiser, 1989):

$$
C=T_{C} / T_{S}
$$

The rupture complexity is a measure of additional energy radiated at frequencies above the corner frequency; and therefore it reflects the high frequency ground motion (Kaiser et al., 1996). When the radiated spectrum can be described by the omega square model, it is expected that $\mathrm{T}_{\mathbf{c}}$ and $\mathrm{T}_{\mathrm{S}}$ are identical and $\mathrm{C}=1$. In practice, 
the value of complexity $(\mathrm{C})$ tends to vary from 0.5 to 2.5 for intermediate and large earthquakes (Kaiser, 1989). Following McGarr, 1981, the value of complexity (C) can be interpreted in terms of asperity model assuming inhomogeneous fault model. This model consists of failure of asperity of radius $a_{i}$ within an annular faulted region of outer radius $a_{0}$, followed by a broader scale dynamic readjustment of the whole fault plane. Knowing $\mathrm{C}$ permits to calculate the ratio between the most energetic asperity radius and the overall source radius $a_{0} / a_{i}$ from the following equation:

$$
\frac{a_{0}}{a_{i}}=5.7(4 C-3)
$$

Assuming that an annular region $a_{i}<a<a_{0}$ has been failed under an ambient fault stress, $\sigma_{a f}$ preceding the earthquake. $\sigma_{a f}$ measures the difference between the regional applied shear stress and the frictional stress that resist sliding across the fault zone. Essentially, the asperity fails with a stress drop ( $\Delta \sigma_{i}$ ) that is in many times larger than the stress drop corresponding to the total zone of faulting, $\Delta \sigma$. The source parameters of the small dimension failure can be determined according to McGarr, 1981. The small scale stress drop $\Delta \sigma_{i}$ is;

$$
\Delta \sigma_{i}=\frac{2}{3} \Delta \sigma\left(\frac{a_{0}}{a_{i}}\right)^{2}
$$

The corresponding average displacement owing to the failure of asperity is;

$$
D_{i}=\frac{1.52}{\pi} \frac{\Delta \sigma}{\mu} \frac{a_{0}^{2}}{a_{i}}
$$

The ambient fault stress $\sigma_{a f}$ is given approximately by;

$$
\sigma_{a f}=\frac{2}{3} \Delta \sigma \frac{a_{0}}{a_{i}}\left[1+0.06 \frac{a_{i}}{a_{0}}+0.33\left[\frac{a_{i}}{a_{0}}\right]^{2}+0.04\left[\frac{a_{i}}{a_{0}}\right]^{3}\right]
$$

\section{Data analysis}

The waveform Data used in this study was retrieved from Incorporated Institutions for Seismology (IRIS) to estimate the spectral magnitudes, magnitude 
spectra and source parameter for the 1990 Sudan and the 2005 Tanganyika Lake earthquakes. For the Sudan earthquake, only high quality seven seismograms recorded at teleseismic distances $\left(40^{\circ}<\mathrm{D}<50^{\circ}\right)$ were available. For Lake Tanganyika earthquake, data was used from 22 stations at epicentral distances between $40^{\circ}$ and $88^{\circ}$. Table. 1 shows the parameters of the two earthquakes. The stations used in this study and azimuth to each station are shown in Table 3 and Table 4. Choice of the records is mainly based on their clarity and absence of noise. These records were instrumentally corrected prior to processing. The spectral magnitudes and the magnitude spectra for each one of the two earthquakes were computed by applying the PASTA program developed by Roslov, 1994 to a time window of 60 seconds, started 5 seconds before the P-wave onset. A $10 \%$ cosine tapering window is applied at both ends of the signal. The spectral magnitudes of the two earthquakes are calculated for each individual station in the period intervals with a moving average window of one octave wide with central periods of $0.25,0.5,1,2,4,8,16$ and 32 second. Consequently, the spectral magnitudes of each earthquake are averaged. The average spectral magnitude values and their corresponding corner periods for the two earthquakes are listed in Table. 2. The plots of the spectral magnitudes for the two earthquakes as a function of the periods are shown in Figures 2 and 3 .

In parallel, the source parameters for each earthquake were determined from the magnitude spectra recorded at different stations with different azimuths, using the corner period. Figure 4 shows the magnitude spectra of two waveforms recorded at different azimuths for the 1990 Sudan earthquake. The magnitude spectrum for three waveform data recorded at different azimuths for the 2005 Tanganyika Lake earthquake is presented in Figure. 5. The determined source parameters for these two earthquakes are presented in Tables 3 and 4. The seismic moment, $M_{O}$, and fault length were determined from equations (2) and (3) respectively, using the corner period. $\mathbf{T}_{\mathbf{0}}$ is replaced by $\mathbf{T}_{\mathbf{C}}$ in equations (2) and (3) when $\mathbf{T}_{\mathbf{C}}$ is used for estimating the seismic moment. The stress drop $\Delta \boldsymbol{\sigma}$ and displacement $\mathrm{D}_{\mathbf{0}}$ were also estimated using equations (4) and (5) respectively. The radiated seismic energy of the P-wave was determined from equations (7) and (8). The spectral complexity for the 1990 Sudan earthquake and the 2005 Lake Tanganyika earthquake was also investigated in terms of asperity model of the source using equations (10), (11), (12), (13) and (14). The obtained results are summarized in Table. 5. 
Table 1. Epicentral parameters of the two analyzed earthquakes.

\begin{tabular}{|c|c|c|c|c|c|c|c|c|}
\hline $\begin{array}{c}\text { Event } \\
\text { no. }\end{array}$ & Date & O.T & Lat. & Long. & Depth & $\mathrm{m}_{\mathrm{b}}(\mathrm{ISC})$ & $\mathrm{m}_{\mathrm{b}}(\mathrm{NEIC})$ & $\begin{array}{c}\mathrm{M}_{\mathrm{S}} \\
\text { ( Harvard) }\end{array}$ \\
\hline 1 & 19900520 & 022201.18 & 05.071 & 32.160 & 15 & 6.5 & 6.7 & 7.2 \\
\hline 2 & 20051205 & 121952.36 & -06.149 & 29.785 & 18 & & 6.4 & 7.2 \\
\hline
\end{tabular}

Table 2. Average values of the spectral magnitudes for the two earthquakes listed in Table.1.

\begin{tabular}{|c|c|l|l|l|l|l|l|l|l|}
\hline Event no. & Period & 0.25 & 0.5 & 1.0 & 2.0 & 4.0 & 8.0 & 16.0 & 32.0 \\
\hline 1 & $\mathrm{~m}_{\mathrm{f}}$ & 5.30 & 5.44 & 5.96 & 6.39 & 6.79 & 6.44 & 6.69 & 6.11 \\
& & \pm 0.07 & \pm 0.04 & \pm 0.05 & \pm 0.05 & \pm 0.05 & \pm 0.04 & \pm 0.05 & \pm 0.05 \\
\hline 2 & $\mathrm{~m}_{\mathrm{f}}$ & 5.10 & 5.45 & 6.00 & 6.26 & 6.33 & 6.18 & 6.20 & 5.07 \\
& & \pm 0.05 & \pm 0.05 & \pm 0.03 & \pm 0.04 & \pm 0.05 & \pm 0.05 & \pm 0.05 & \pm 0.08 \\
\hline
\end{tabular}

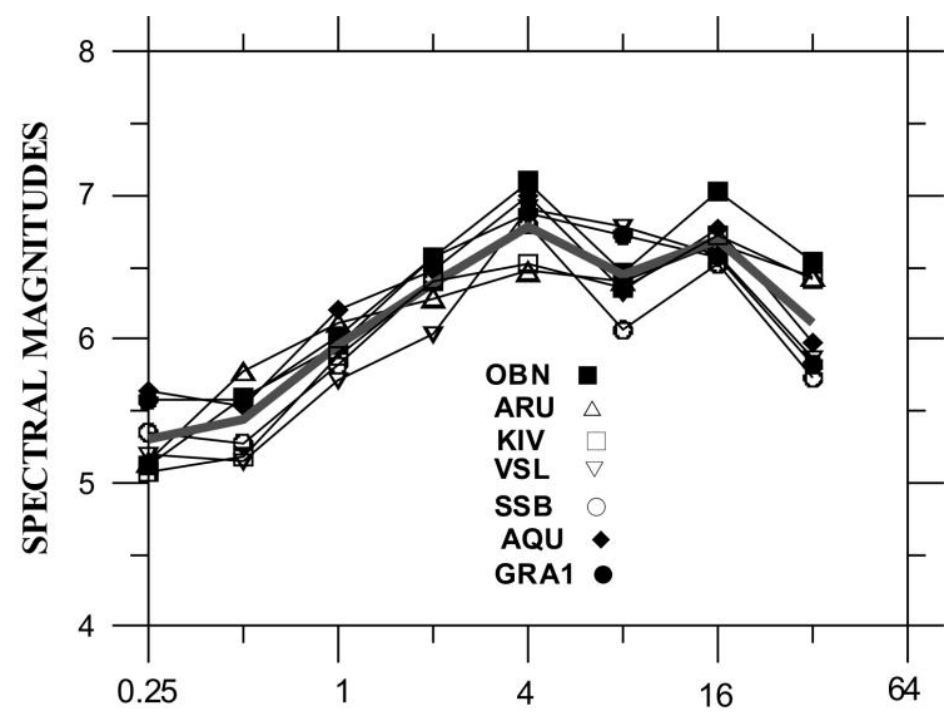

PERIOD (Sec.)

Fig.2. Spectral magnitudes for the individual stations of the 1990 Sudan earthquake and their average measurements (heavy line). 


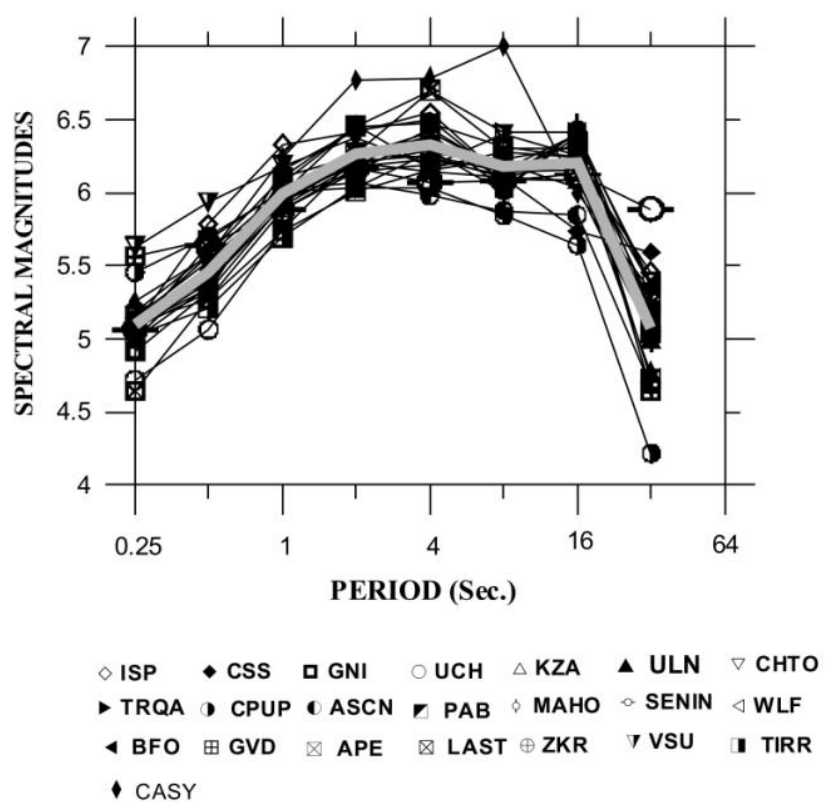

Fig.3. Spectral magnitudes for the individual stations of the 2005 Tanganyika Lake earthquake and their average values (heavy line).

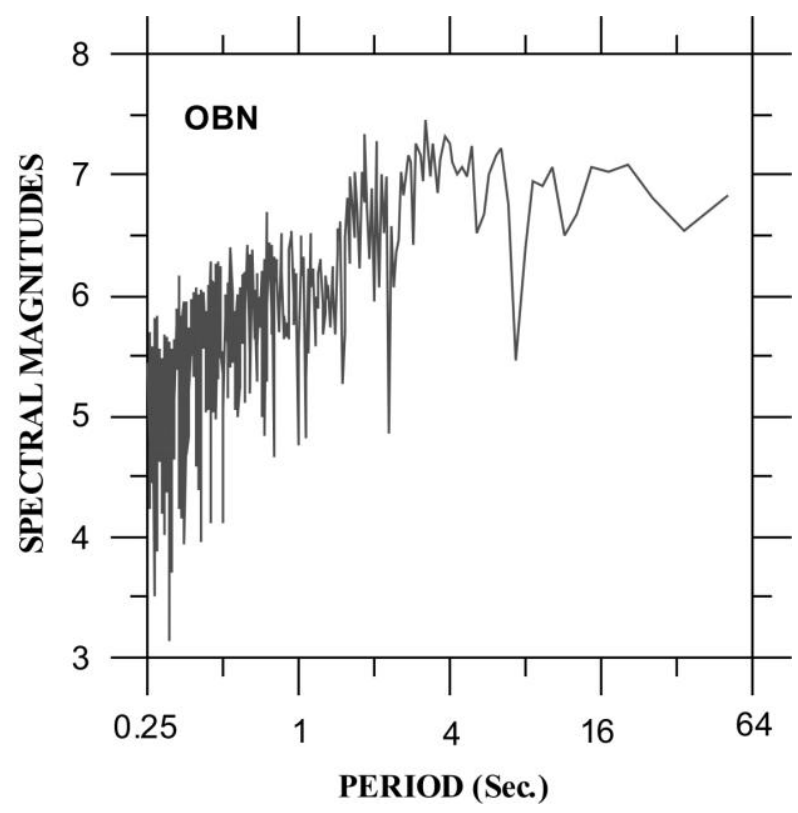




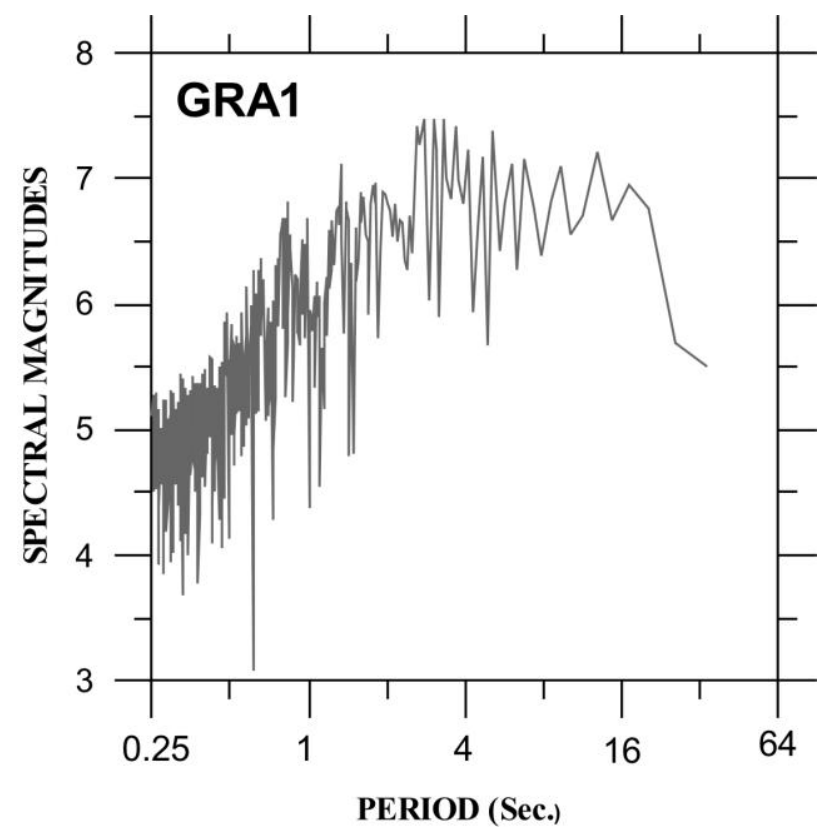

Fig.4. Magnitude spectra for some broadband records of the Sudan 1990 earthquake.

Table 3. Source parameters derived from the magnitude spectra of the May, 221990 Sudan earthquake

\begin{tabular}{|c|c|c|c|c|c|c|c|c|c|c|c|c|}
\hline Station & Azimuth & $\begin{array}{c}\text { Delta in } \\
\text { Degree }\end{array}$ & $\begin{array}{c}\mathrm{m}_{\mathrm{f}} \\
(\mathrm{max})\end{array}$ & $\begin{array}{c}\mathrm{E}_{\mathrm{p}} \\
\left(10^{12} \mathrm{~J}\right)\end{array}$ & $\begin{array}{c}\mathrm{T}_{\mathrm{o}} \\
(\mathrm{Sec} .)\end{array}$ & $\begin{array}{c}\mathrm{T}_{\mathrm{C}} \\
(\mathrm{Sec} .)\end{array}$ & $\begin{array}{c}\mathrm{T}_{\mathrm{S}} \\
(\mathrm{Sec})\end{array}$ & $\mathrm{C}$ & $\begin{array}{c}\mathrm{M}_{\mathrm{o}} \\
\left(10^{18} \mathrm{Nm}\right)\end{array}$ & $\begin{array}{c}\mathrm{L} \\
(\mathrm{KM})\end{array}$ & $\begin{array}{c}\mathrm{D} \\
(\mathrm{M})\end{array}$ & $\begin{array}{c}\Delta \sigma \\
(\mathrm{MPa})\end{array}$ \\
\hline OBN & 03.2 & 49.90 & 7.46 & 12.90 & 3.20 & 7.00 & 4.18 & 1.63 & 9.99 & 30.04 & 0.52 & 1.29 \\
\hline KIV & 11.7 & 39.70 & 7.41 & 03.52 & 6.39 & 7.00 & 12.2 & 0.58 & 8.90 & 30.04 & 0.47 & 1.15 \\
\hline ARU & 17.3 & 55.20 & 7.10 & 02.09 & 6.02 & 4.75 & 4.91 & 0.92 & 2.96 & 20.39 & 0.34 & 1.22 \\
\hline VSL & 332.3 & 40.20 & 7.57 & 08.71 & 3.00 & 6.88 & 10.29 & 0.66 & 12.60 & 29.52 & 0.68 & 1.72 \\
\hline SSB & 333.4 & 47.00 & 7.40 & 09.61 & 3.30 & 6.46 & 4.26 & 1.51 & 8.03 & 27.27 & 0.49 & 1.32 \\
\hline AQU & 338.7 & 40.80 & 7.46 & 05.90 & 3.79 & 4.57 & 9.17 & 0.50 & 6.52 & 19.61 & 0.79 & 3.02 \\
\hline GRA1 & 341.7 & 47.80 & 7.49 & 07.90 & 3.00 & 6.00 & 7.88 & 0.76 & 9.17 & 25.75 & 0.65 & 1.88 \\
\hline & & & 7.4 & 07.23 & 4.10 & 6.09 & 7.56 & 0.94 & 8.31 & 26.09 & 0.56 & 1.65 \\
\pm & \pm \\
Aver. & & & \pm & \pm & \pm & \pm & \pm & \pm & \pm & \pm & \pm \\
& & & 0.04 & 0.81 & 0.32 & 0.30 & 0.70 & 0.10 & 0.65 & 0.97 & 0.03 & 0.14 \\
\hline S.D & & & 0.02 & 03.71 & 1.47 & 1.04 & 3.2 & 0.45 & 3.00 & 4.45 & 0.15 & 0.66 \\
\hline
\end{tabular}


Table 4. Source parameters derived from the magnitude spectra of the December, 52005 Taganyika earthquake.

\begin{tabular}{|c|c|c|c|c|c|c|c|c|c|c|c|c|}
\hline Station & Azimuth & $\begin{array}{c}\text { Delta } \\
\text { In } \\
\text { Degree }\end{array}$ & $\underset{(\max )}{\mathrm{m}_{\mathrm{f}}}$ & $\begin{array}{c}E_{p} \\
\left(10^{12} J\right)\end{array}$ & $\begin{array}{c}\mathrm{T}_{\mathrm{o}} \\
\mathrm{Sec}\end{array}$ & $\begin{array}{c}\mathrm{T}_{\mathrm{C}} \\
\mathrm{Sec}\end{array}$ & $\begin{array}{c}\mathrm{T}_{\mathrm{S}} \\
\mathrm{Sec}\end{array}$ & C & $\begin{array}{c}\mathrm{M}_{\mathrm{O}} \\
\left(10^{18}\right. \\
\mathrm{Nm})\end{array}$ & $\begin{array}{c}\mathrm{L} \\
(\mathrm{KM})\end{array}$ & $\begin{array}{c}\mathrm{D} \\
(\mathrm{M})\end{array}$ & $\begin{array}{c}\Delta \sigma \\
\mathrm{MPa}\end{array}$ \\
\hline ISP & 00.0 & 43.84 & 7.27 & 4.40 & 1.29 & 2.81 & 3.06 & 0.92 & 2.59 & 12.06 & 0.84 & 5.16 \\
\hline CSS & 04.0 & 41.09 & 7.13 & 2.88 & 1.07 & 3.48 & 4.10 & 0.84 & 2.32 & 14.94 & 0.49 & 2.44 \\
\hline GNI & 15.0 & 48.14 & 7.14 & 2.81 & 2.50 & 3.65 & 4.40 & 0.83 & 2.49 & 15.67 & 0.48 & 2.27 \\
\hline $\mathrm{UCH}$ & 35.0 & 63.07 & 7.00 & 1.60 & 2.76 & 3.88 & 4.20 & 0.92 & 1.92 & 16.65 & 0.33 & 1.45 \\
\hline KZA & 36.0 & 63.41 & 6.96 & 1.06 & 3.65 & 3.54 & 4.80 & 0.73 & 1.60 & 15.19 & 0.32 & 1.59 \\
\hline ULN & 41.0 & 86.07 & 7.20 & 2.54 & 2.09 & 2.89 & 4.33 & 0.68 & 3.14 & 17.17 & 0.50 & 2.17 \\
\hline CHTO & 68.0 & 72.49 & 6.96 & 1.00 & 1.18 & 3.15 & 5.41 & 0.58 & 1.43 & 13.51 & 0.37 & 2.01 \\
\hline CASY & 156.0 & 80.60 & 7.53 & 17.6 & 2.44 & 5.24 & 4.23 & 1.24 & 8.79 & 22.49 & 0.82 & 2.70 \\
\hline TRAQ & 232.0 & 87.63 & 7.20 & 4.20 & 2.88 & 4.16 & 4.99 & 0.83 & 3.26 & 17.85 & 0.48 & 2.00 \\
\hline CPUP & 244.00 & 84.74 & 6.80 & 0.88 & 1.53 & 2.37 & 2.92 & 0.80 & 0.73 & 10.17 & 0.33 & 2.46 \\
\hline ASCN & 256.00 & 43.87 & 6.90 & 0.88 & 2.62 & 2.37 & 4.67 & 0.51 & 0.93 & 10.17 & 0.42 & 3.09 \\
\hline PAB & 328.00 & 55.41 & 6.78 & 0.67 & 1.50 & 4.24 & 6.11 & 0.70 & 1.26 & 18.19 & 0.18 & 0.73 \\
\hline MAHO & 334.00 & 51.59 & 7.05 & 1.69 & 1.76 & 4.52 & 4.83 & 0.90 & 2.50 & 19.39 & 0.31 & 1.20 \\
\hline SENIN & 341.00 & 56.06 & 6.95 & 0.96 & 1.31 & 3.12 & 5.33 & 0.59 & 1.38 & 13.39 & 0.36 & 2.00 \\
\hline WLF & 342.00 & 59.35 & 7.03 & 1.55 & 1.20 & 3.69 & 6.10 & 0.61 & 1.95 & 15.84 & 0.37 & 1.72 \\
\hline $\mathrm{BFO}$ & 343.00 & 57.51 & 6.88 & 1.21 & 1.68 & 3.53 & 3.09 & 1.14 & 1.33 & 15.15 & 0.27 & 1.33 \\
\hline GVD & 352.00 & 41.20 & 7.21 & 2.48 & 2.84 & 3.53 & 6.90 & 0.48 & 2.83 & 15.15 & 0.58 & 2.85 \\
\hline APE & 354.00 & 43.25 & 7.10 & 3.43 & 3.20 & 4.97 & 3.00 & 1.66 & 2.89 & 21.33 & 0.30 & 1.04 \\
\hline LAST & 354.00 & 41.36 & 7.07 & 1.79 & 3.30 & 4.20 & 4.01 & 1.04 & 2.44 & 18.03 & 0.35 & 1.46 \\
\hline ZKR & 355.00 & 41.25 & 7.15 & 2.86 & 3.41 & 3.60 & 4.50 & 0.79 & 2.52 & 15.45 & 0.50 & 2.39 \\
\hline VSU & 358.00 & 64.52 & 7.10 & 2.95 & 1.33 & 2.24 & 3.43 & 0.65 & 1.40 & 09.61 & 0.71 & 5.49 \\
\hline TIRR & 358.00 & 50.46 & 6.82 & 0.82 & 3.4 & 4.50 & 3.43 & 1.33 & 1.36 & 17.81 & 0.20 & 0.84 \\
\hline Aver. & & & $\begin{array}{c}7.0 \\
\pm \\
0.03\end{array}$ & $\begin{array}{c}2.73 \\
\pm \\
0.75\end{array}$ & $\begin{array}{c}2.22 \\
\pm \\
0.18\end{array}$ & $\begin{array}{c}3.62 \\
\pm \\
0.17\end{array}$ & $\begin{array}{c}4.44 \\
\pm \\
0.23\end{array}$ & $\begin{array}{c}0.85 \\
\pm \\
0.06\end{array}$ & $\begin{array}{c}2.32 \\
\pm \\
0.34\end{array}$ & $\begin{array}{c}15.69 \\
\pm \\
0.72\end{array}$ & $\begin{array}{c}0.43 \\
\pm \\
0.04\end{array}$ & $\begin{array}{c}2.20 \\
\pm \\
0.26\end{array}$ \\
\hline S.D & & & 0.18 & 3.50 & 0.87 & 0.81 & 1.08 & 0.29 & 1.62 & 03.37 & 0.18 & 1.19 \\
\hline
\end{tabular}

Table 5. Average source parameters determined from magnitude spectra of the two earthquakes listed in Table. 1 considering $T_{C}$ and $C$.

\begin{tabular}{|c|c|c|c|c|c|c|c|c|c|c|c|c|c|}
\hline $\begin{array}{c}\text { Event } \\
\text { No. }\end{array}$ & $\begin{array}{c}\mathrm{E}_{\mathrm{p}} \\
\left(10^{12} \mathrm{~J}\right)\end{array}$ & $\mathrm{m}_{\mathrm{f}}$ & $\begin{array}{c}\mathrm{T}_{\mathrm{c}} \\
(\mathrm{s})\end{array}$ & $\begin{array}{c}\mathrm{M}_{\mathrm{O}} \\
\left(10^{18} \mathrm{Nm}\right)\end{array}$ & $\begin{array}{c}\mathrm{L} \\
(\mathrm{Km})\end{array}$ & $\begin{array}{c}\mathrm{Do} \\
(\mathrm{m})\end{array}$ & $\begin{array}{c}\Delta \sigma \\
(\mathrm{MPa})\end{array}$ & $\mathrm{C}$ & $\mathrm{a}_{\mathrm{o}} / \mathrm{a}_{\mathrm{i}}$ & $\begin{array}{c}\mathrm{a}_{\mathrm{I}} \\
(\mathrm{Km})\end{array}$ & $\begin{array}{c}\mathrm{D}_{\mathrm{i}} \\
(\mathrm{m})\end{array}$ & $\begin{array}{c}\Delta \sigma_{\mathrm{i}} \\
(\mathrm{MPa})\end{array}$ & $\begin{array}{c}\sigma_{\text {aff }} \\
(\mathrm{MPa})\end{array}$ \\
\hline 1 & 07.23 & 7.41 & 6.09 & 08.31 & 26.09 & 0.56 & 1.65 & 0.94 & 4.33 & 3.01 & 1.67 & 20.75 & 4.94 \\
\hline 2 & 02.37 & 7.06 & 3.62 & 02.32 & 15.69 & 0.43 & 2.20 & 0.85 & 2.28 & 3.54 & 0.72 & 07.66 & 3.67 \\
\hline
\end{tabular}

Results And Discussion 
In this study, the average maximum spectral magnitude, the source parameters and the complexity of May, 20, 1990 Sudan and the December, 05, 2005 Tanganyika Lake earthquakes which are located at the East African Rift System were derived from their magnitude spectrum. The obtained average parameters are determined from broadband seismograms recorded at various azimuths and epicentral distances in order to have stability in the estimated values. The average spectral magnitudes of 1990 Sudan earthquake show that the maximum value of the average spectral magnitude is 6.79 that corresponds to a corner period of 4 seconds while the 2005 Tanganyika lake gives a maximum spectral magnitude of 6.33 at a corner period of 4 seconds. Although the two events are similar in surface wave magnitude $\left(M_{S}=7.2\right)$, the characteristic shape of the average spectral magnitudes for the 1990 Sudan earthquake is clearly different from that of the 2005 Tanganyika Lake one.

For both earthquakes, $\mathbf{T}_{\mathbf{C}}$ is generally larger than $\mathbf{T}_{\mathbf{0}} . \mathrm{T}_{\mathrm{C}}$ also shows a smaller amount of scatter than $\mathbf{T}_{\mathbf{0}}$ throughout the individual stations. The average $\mathbf{T}_{\mathbf{C}}$ value for the two events is about 1.5 times larger than the $\mathbf{T}_{\mathbf{0}}$ (Tables 3 and 4). For the 1990 Sudan earthquake, the standard deviation is about $17 \%$ for $\mathbf{T}_{\mathbf{C}}$ and $36 \%$ for $\mathbf{T}_{\mathbf{0}}$ (Table. 3). The standard deviation of the corner period $\mathbf{T}_{\mathbf{C}}$ for the 2005 Tanganyika Lake earthquake is about $20 \%$ and $40 \%$ for $\mathbf{T}_{\mathbf{0}}$. The existence of such scatter in the corner period may also be attributed to the near station site characteristics which seem to have more effects especially on the complex spectrum. Since the estimation of the seismic moment and stress drop is mainly dependant on the corner period, the existence of the corner frequency error factor will propagate through the obtained values. The relatively higher stability of $\mathbf{T}_{\mathbf{C}}$ results from the integration of the spectrum as pointed out by Boatwright, 1980, Snoke et al., 1983, Andrews, 1986 and Kaiser et al., 1996. Due to stability of the $\mathbf{T}_{\mathbf{C}}$, its values were preferred for estimating the seismic moment, stress drop and fault length for both earthquakes. The average corner period $\mathbf{T}_{\mathbf{C}}$, for 1990 Sudan earthquake (6.09 seconds) is larger than that of the 2005 Tanganyika lake one with $\mathrm{T}_{\mathrm{C}}$ equal to 3.62 seconds (Tables $3 \& 4)$. These values of $\mathrm{T}_{\mathrm{C}}$ give faults having lengths of 26.09 and $15.69 \mathrm{~km}$ respectively. The average seismic moment of the 1990 Sudan earthquake $(8.31 \mathrm{x}$ $10^{18} \mathrm{Nm}$ ) is about 3.5 times larger than the 2005 Tanganyika Lake earthquake of average seismic moment $\left(2.32 \times 10^{18} \mathrm{Nm}\right)$. In comparison, the estimated stress drops are found to be 1.65 MPa for the 1990 Sudan earthquake and 2.20 MPa for the 2005 Tanganyika Lake. These quantities, which are calculated for each earthquake, are listed in Tables 3 and 4 . The values of $\mathrm{M}_{\mathrm{O}}$, estimated from the magnitude spectrum 
for both earthquakes, differ from those reported one by CMT. For the 1990 Sudan earthquake, the average seismic moment $\left(8.31 \times 10^{18} \mathrm{Nm}\right)$ is about ten times smaller than the moment estimated from CMT of Harvard $\left(8.20 \times 10^{19} \mathrm{Nm}\right)$ and six times smaller than the one estimated by Gaulon et al.,1992 from the waveform modeling of the teleseismic broadband $\mathrm{P}$ and $\mathrm{SH}\left(5.30 \times 10^{19} \mathrm{Nm}\right)$. The estimated seismic moment for the 2005 Tanganyika lake earthquake $\left(2.32 \times 10^{18} \mathrm{Nm}\right)$ is eight times smaller than that estimated from CMT of Harvard $\left(1.81 \times 10{ }^{19} \mathrm{Nm}\right)$. The relatively smaller values of moments obtained in this study compared to CMT is probably due to the fact that the present solutions are based on the P-wave only.

For the 1990 Sudan earthquake, the magnitude spectra at GRA1 station which is nearly located in the direction of the NW trending fault plane shows a distortion of the spectrum of the intermediate periods (Fig. 4) compared to OBN station which is located at an angle of about $20^{\circ}$ clockwise from the GRA1 station. These changes in magnitude spectra characteristics may be due to directivity. Unfortunately, the azimuth coverage of the stations is insufficient for monitoring the effect of the directivity on the magnitude spectra. The magnitude spectra of the 2005 Tanganyika lake earthquake for waveform records at three different azimuths (Fig. 5) show some evidences of the frequency dependent directivity. CASY station shows relatively larger amplitude of the spectrum at intermediate periods compared to the two other stations. It also reflects a sharp decay of the spectrum from intermediate to lower periods relative to PFO station which is located opposite to CASY one. The radiated seismic energy is also focused towards the azimuth of this station, whereas the seismic energy at this station is the maximum estimated value compared to the other stations which are located away from the rupture direction. This means that CASY station is located in the direction of the main rupture propagation. The predicted direction of the rupture is in good agreement with the direction of the NW trending fault plane. However, ULN station which is located perpendicular to the main rupture shows the spectral decay as $\boldsymbol{w}^{2}$ model with a nearly flat spectral magnitude level. The changes of the spectral shapes at different stations located in various azimuths with respect to the direction of the rupture propagation may be related to the frequency dependent directivity according to the self similar $\mathrm{k}^{2}$ distribution model of the coseismic slip deduced by Bernard and Herrero, 1994. The predicted direction of the rupture is in good agreement with the direction of the NW trending fault plane.

The two investigated earthquakes in this study have intermediate complexity Cvalues (Table. 5). The value of the relative asperity size $\mathbf{a}_{\mathbf{O}} / \mathbf{a}_{\mathbf{I}}$, which reflects the 
non-uniform distribution of various physical properties on the fault plane for the 1990 Sudan earthquake is 1.5 times lager than the 2005 Tanganyika Lake one. The localized stress drop $\Delta \boldsymbol{\sigma}_{\mathbf{i}}$ is larger by a factor of 3 for the 1990 Sudan earthquake compared to that of the 2005 Tanganyika Lake although, the $\Delta \boldsymbol{\sigma}$ of the second event is 1.3 times larger than the value of the first event. The local stress drop $\Delta \sigma_{\mathbf{i}}$ for the first event is higher than the average stress drop $\Delta \boldsymbol{\sigma}$ over the fault by a factor of 12 whereas the estimated localized stress drop $\Delta \boldsymbol{\sigma}_{\mathbf{i}}$ for the second event is larger than the average stress drop $\Delta \sigma$ by a relatively smaller factor (3.5). These results are in a good agreement with the estimated values of complexity $\mathrm{C}$ which indicate that The 1990 Sudan earthquake is more complex compared to that of the 2005 Tanganyika Lake. For complex sources, the average static stress drop $\Delta \boldsymbol{\sigma}$ is insufficient to describe the regional stress field. Therefore, the ambient faulting stress $\sigma_{\text {aff }}$ which determines the level of stress accumulation within a seismogenic province (McGarr, 1981) and represents the regional shear stress which can cause displacement along the fault (Kaiser et al., 1996), is determined for both earthquakes. $\sigma_{\text {aff }}$, for the 1990 Sudan earthquake is about 1.3 times larger than the value for 2005 Tanganyika Lake. The quantities of stress drop, ambient stress drop and localized stress drop are given in Table. 5. Variations in the stress drop and ambient stress drop for the two investigated earthquakes is mainly related to the different tectonic environments where these earthquakes took place. The CMT solutions by Harvard for both earthquakes support this result. However, the focal mechanism solution of the 1990 Sudan earthquake corresponds to strike slip faulting, while the 2005 Lake Tanganyika is a pure normal faulting mechanism.

\section{References}

1. AKI, K., 1967. Scaling low of seismic spectrum. J.Geophys.Res.72,1217-1231.

2. Ambraseys, N.N. and Adams, R.D.,1986. Seismicity of the Sudan. Bulletin of the Seismological Society of America, 76, 483 - 493

3. ANDREWS, D.J., 1986. Objective determination of source parameters and similarity of earthquakes of different size. In: S. Das, J. Boatwright, and C.H.Scholz (Eds), Earthquake source mechanism. Geophysical Monograph 37, Maurice Ewing, 6, Geophys. Un., Wash. D. C.,259-267.

4. BARAZANGI, M., 1983. A summary of seismotectonics of the Arab region. In : Assessment and mitigation of earthquake risk in the Arab region, Cidlinsky, K. and Rouhban, B.M.(editors)., 43-77. 
5. BERNARD, P. AND HERRERO, A. 1994. Slip heterogeneity, body-wave spectra, and directivity of earthquake ruptures. Annali .Di Geofis., XXXVII,6,1679-1690.

6. BOATWRIGHT, J., 1980. A spectral theory for circular seismic sources; simple estimates of source dimension, dynamic stress drop, and radiate seismic energy. Bull. Seism.Soc. Am., 70, 1-27.

7. BRUNE, J.N., 1968. Seismic moment, seismicity and the rate of slip along major fault zones. J.Geophys.Res.73, 777-784.

8. BRUNE, J.N., 1970. Tectonic stress and the spectra of seismic shear waves from earthquakes. J.Geophys.Res., 75,4997-5009.

9. BRUNE, J.N., 1971. Correction, J.Geophysics.Res.,76, 5002.

10. CHOWDHURY, D. K. and DUDA, S.J., 1986. Broadband seismograms,band -pass seismograms and spectral magnitudes for a selection of 1979, 1980 and 1981 earthqukes. Institute fur Geophysik, Universitat Hamburg, 180 pp.

11. DUDA, S.J., AND KAISER, D.,1989.Spectral magnitudes, magnitude spectra, and earthquake quatification; The stability issue of corner period and the maximum magnitude for a given earthquake. Tectonophysics, 166, 205-219.

12. DUDA, S.J., AND T.B. YANOVSKAYA, 1994. Calibration functions for P-wave spectral magnitudes. Acta Geophysica Polonica, XLII, No.4, 293-306.

13. GAUlON, R., CHOROWICZ, J., VIDAL, G.,ROMANOWICZ, B. AND ROULT, G., 1992. Regional geodynamic implications of the May-July 1990 earthquake sequence in southern Sudan. Tectonophysics, 209, 87-103.

14. GIRDLER , R.W., AND MCCONELL, D.A., 1994. The 1990 to 1991 Sudan earthquake sequence and the extent of the East African Rift System. Science, 264, 67-69.

15. KAISER,D., 1989. Seismizitat des Erdkorpers: Magitudenspektren und andere ErdbebenHer-dparameter aufgrund von Breitband-Seismogrammen.Ph.D.-Thesis,Universitat, Hamburg.

16. KAISER, D., AND DUDA, S.J., 1986. Broadband seismograms, band-pass seismograms, and spectral magnitudes for a selection of 1978 earthquakes. Institute fur Geophysik, Universitat Hamburg, 61pp.

17. KAISER, D., AND DUDA, S.J., 1988. Magnitude spectra and other source parameters for some major 1985 and 1986 earthquakes. In:O.Kulhanek(Ed.), Seismic source physics and earthquake prediction research. Tectonophysics,152,203-218. 
18. KAISER, D., DUDA, J.S. AND CHOWDHURY, D. K., 1996. P-wave magnitude spectra, stress drops, rupture complexities and other source parameters from broadband seismograms of three 1987 Southern California earthquakes. Geofizka, 13,1-29.

19. KEILIS-BOROK, V., 1959. On the estimation of the displacement in an earthquake source and of source dimension. Annali .Di Geofis.12,205-214.

20. MCGARR, A., 1981. Analysis of Peak ground motion in terms of model of inhomogeneous faulting. J.Geophys.Res., 86, B5,3901-3912.

21. OXBURG, E.R., AND TURCOTTE, D.L., 1974. Membrance tectonics and the East African Rift . Earth. Planet.Sci.Lett.,22, 133-140.

22. ROLET, J., MONDEGUER, A.,BOUROULlEC, J., BANDORA, T., COUSSEMENT, J. AND TIERCELIN, J., 1991.Structure and different kinematic development faults along the Lake Tanganyika Rift Valley, East African Rift System. Bulletin Centres Rech. Explor.-Prod Elf-Aquitaine, 15,327-342.

23. ROSLOV, Y., 1994. Program for amplitude spectrum treatment and analysis. Acta Geophyscia Plonica, XL 11,4,315-319.

24. SARKER, D., AND DUDA, S.J., 1985. Spectral P-wave magnitudes, Aki's omega-square model and source parameters of earthquakes. Tectonophysics, 188, 175-193.

25. SNOKE, J.A., LINDE, A. T., AND SACKS, I.S., 1983. Apperent stress: an estimate of the stress drop. Bull.Seism.Soc.Am., 73,339-348.

26. SNOKE, J. A., 1987. Stable determination of Brune stress drops. Bull. Seism. Soc. Am., 79, 493-499. 